\title{
On the Use of Explosion Records for Examining Earthquake Location Uncertainty in Taiwan
}

\author{
Yih-Min $\mathrm{Wu}^{1,{ }^{*}}$, Chien-Hsin Chang ${ }^{2}$, Hao Kuo-Chen ${ }^{3}$, Hsin-Hua Huang ${ }^{1}$, and Chien-Ying Wang ${ }^{3}$ \\ ${ }^{1}$ Department of Geosciences, National Taiwan University, Taipei, Taiwan \\ ${ }^{2}$ Central Weather Bureau, Taipei, Taiwan \\ ${ }^{3}$ Institute of Geophysics, National Central University, Jhongli, Taiwan
}

Received 24 August 2012, accepted 31 January 2013

\begin{abstract}
Signals from ten explosions were used to examine earthquake location uncertainty in Taiwan. Location errors for explosion sites determined using a relocation process were expressed in terms of statistical measurements for standard errors in the depth (ERZ), the epicenter (ERH), the root-mean-square of the travel time residuals (RMS), and the station coverage gap (GAP). In general, for this study, major factors in location errors resulted from the poor coverage of seismic stations (e.g., a large value of GAP). Using the relationship between location errors and parameters from the explosion location assessment, uncertainties for earthquake locations in the Taiwan region for a total of 384064 events from 1991 to 2011 were evaluated. Offshore regions in southwestern and northeastern Taiwan had larger location errors. For the inland locales, location errors in longitude, latitude, and depth were approximately $3.1 \pm 2.7,1.3 \pm 1.6$, and $4.6 \pm 3.9 \mathrm{~km}$, respectively. The uncertainties estimated from this study could offer a good reference for other related studies.
\end{abstract}

Key words: Earthquake, Seismic network, Earthquake location, Active source

Citation: Wu, Y. M., C. H. Chang, H. Kuo-Chen, H. H. Huang, and C. Y. Wang, 2013: On the use of explosion records for examining earthquake location uncertainty in Taiwan. Terr. Atmos. Ocean. Sci., 24, 685-694, doi: 10.3319/TAO.2013.01.31.01(T)

\section{INTRODUCTION}

The uncertainty of earthquake locations is an important factor in seismological studies especially for identifying seismogenic structures and accessing seismic losses caused by earthquake damage (Wu et al. 2002). Reliable earthquake locations depend on the quality of seismic-wave records' spatial distribution of recording stations, reliability of crustal and upper mantle velocity structures, and the methodology used to locate earthquakes. Statistical measurements of standard errors, the ERZ (the error in the vertical), and the ERH (the error in the horizontal) are commonly calculated in earthquake location programs (Flinn 1965; Lee and Lahr 1975; Chang et al. 2000). However, the importance of these two measurements is generally overlooked (Flinn 1965).

Taiwan is located at the plate boundary between the Eurasian and Philippine Sea plates which have very complicated fault systems with a spacing of just a few kilometers. When considering seismic hazards mitigation in rapid

\footnotetext{
* Corresponding author

E-mail:drymwu@ntu.edu.tw
}

earthquake reporting, the uncertainty of an earthquake location may lead to misidentification of causative faults and may provide an incorrect estimation of damage. Therefore, it is necessary to determine a mechanism for estimating the earthquake location uncertainty in Taiwan. Recently, the Taiwan Integrated GEodynamic Research (TAIGER) project, a large Taiwan-US cooperative research project, was conducted from 2004 - 2009. Scientists from France, Japan, and the Philippines also participated (Kuo-Chen et al. 2012). The TAIGER project employed seismological techniques to image the crustal and upper mantle structures beneath mountain belts and surrounding seas in and around the Taiwan region, and explore mountain building processes, plate boundary dynamics, seismogenic mechanisms, and marine geo-hazards. During the TAIGER project ten dynamite explosions were detonated to imaging Taiwan's crustal structures. Figure 1 provides the locations of the ten shots. Explosion signals recorded by the permanent seismic networks in Taiwan offer a good opportunity for us to investigate the uncertainty of earthquake location. Here, we 
present results for the uncertainty of earthquake location using explosion records.

\section{DATA AND ANALYSIS}

From February 27 to March 5 of 2008, ten explosions were detonated during the TAIGER project in the Taiwan region (Table 1 and Fig. 1). The sizes of the dynamite explosions ranged from 750 to $3000 \mathrm{~kg}$. Table 1 and Fig. 1, respectively, provide detailed parameters as well as the sites of dynamite explosions. Explosion signals were recorded by the Central Weather Bureau Seismic Network (CWBSN), the Broadband Array in Taiwan for Seismology (BATS), and the temporary seismic arrays deployed by the TAIGER project. For this study, such a valuable dataset was used for testing the uncertainty of earthquake location. Figure 1 provides the distribution of the CWBSN, BATS, and TAIGER stations. In the figure, $\mathrm{P}$ arrivals from the ten shots can clearly be identified by visual inspection. Figure 2 provides an example of the signals caused by the $\mathrm{S} 2$ explosion. In general, 33 to 95 stations with an average of 64 stations recorded P arrivals with good signal-to-noise ratios. Since S waves are not expected from explosions, we did not select $\mathrm{S}$ arrivals. Sometimes $\mathrm{P}$ to $\mathrm{S}$ converted waves is observed within the horizontal components. However, they were not helpful for the relocation of explosions.

Chang et al. (2012) pointed out that prior to 2012 the CWBSN system contained an approximate $0.2 \mathrm{sec}$ telemetry latency. In this work, we also checked telemetry delays using explosion signals for the co-site stations of the CWBSN and BATS. Figure 3 provides an example of the explosions recorded by both the CWBSN and BATS stations and indicates that the signals recorded by the CWBSN system were approximately $0.2 \mathrm{sec}$ later than those recorded by the BATS system, since the data of the CWBSN system was given a time mark at the recording center but not in situ. Half of the delay was caused by relays of two modems, while the other half was caused by transmission (Chang et al. 2012). Table 2 displays latencies examined by explosion signals and the test results from Chang et al. (2012). Our

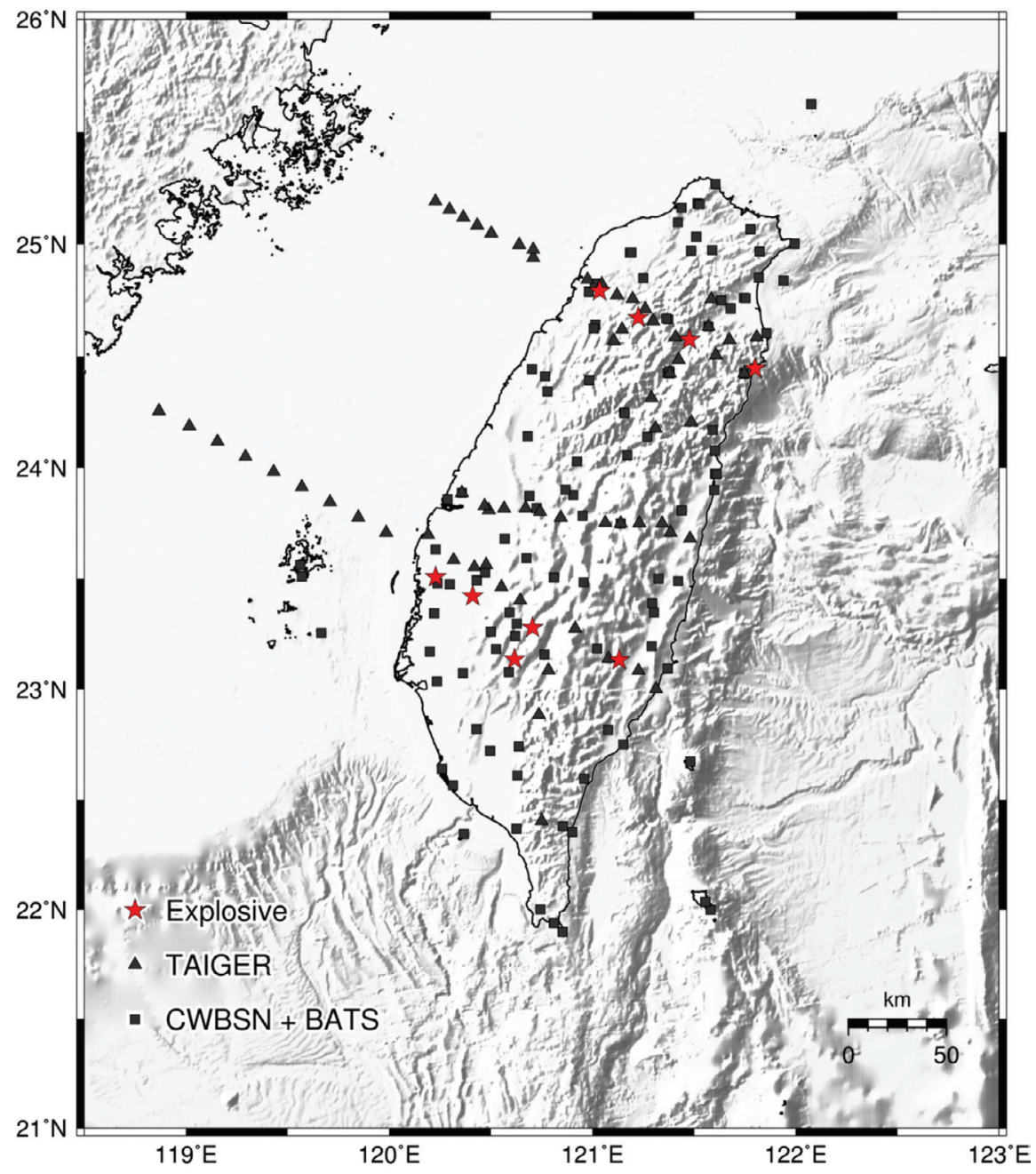

Fig. 1. Distribution of the seismic stations and the explosion sites in this study. 
Table 1. Parameters of the 10 dynamite shots of the TAIGER project.

\begin{tabular}{|cccccccc|}
\hline No. & Site Code & Longitude $\left({ }^{\circ} \mathbf{E}\right)$ & Latitude $\left({ }^{\circ} \mathbf{N}\right)$ & Elevation $(\mathbf{m})$ & Shooting Time $(\mathbf{U T})$ & Size $(\mathbf{k g})$ & $\mathbf{M}_{\mathbf{L}}(\mathbf{C W B})$ \\
\hline 1 & S1 & 120.22990 & 23.51060 & 6 & $2008 / 02 / 2717: 01: 49.486$ & 1000 & 3.02 \\
2 & S2 & 120.41314 & 23.42513 & 20 & $2008 / 02 / 2717: 30: 57.350$ & 750 & 2.62 \\
3 & S3 & 120.70663 & 23.28189 & 650 & $2008 / 02 / 2618: 02: 45.860$ & 500 & 1.89 \\
4 & S3P & 120.61865 & 23.13875 & 335 & $2008 / 02 / 2617: 32: 43.296$ & 1500 & 1.78 \\
5 & S4 & 121.13363 & 23.13466 & 390 & $2008 / 02 / 2817: 02: 08.560$ & 750 & 2.30 \\
6 & N1 & 121.03767 & 24.79534 & 55 & $2008 / 03 / 0617: 03: 23.068$ & 750 & 2.56 \\
7 & N2 & 121.22763 & 24.67742 & 590 & $2008 / 03 / 0617: 34: 56.364$ & 750 & 1.55 \\
8 & N3 & 121.47969 & 24.57874 & 405 & $2008 / 03 / 0418: 01: 17.988$ & 750 & 2.10 \\
9 & N3P & 121.47969 & 24.57874 & 405 & $2008 / 03 / 0417: 01: 17.824$ & 3000 & 2.67 \\
10 & N4 & 121.80352 & 24.44872 & 6 & $2008 / 03 / 0517: 03: 40.008$ & 1000 & 2.43 \\
\hline
\end{tabular}

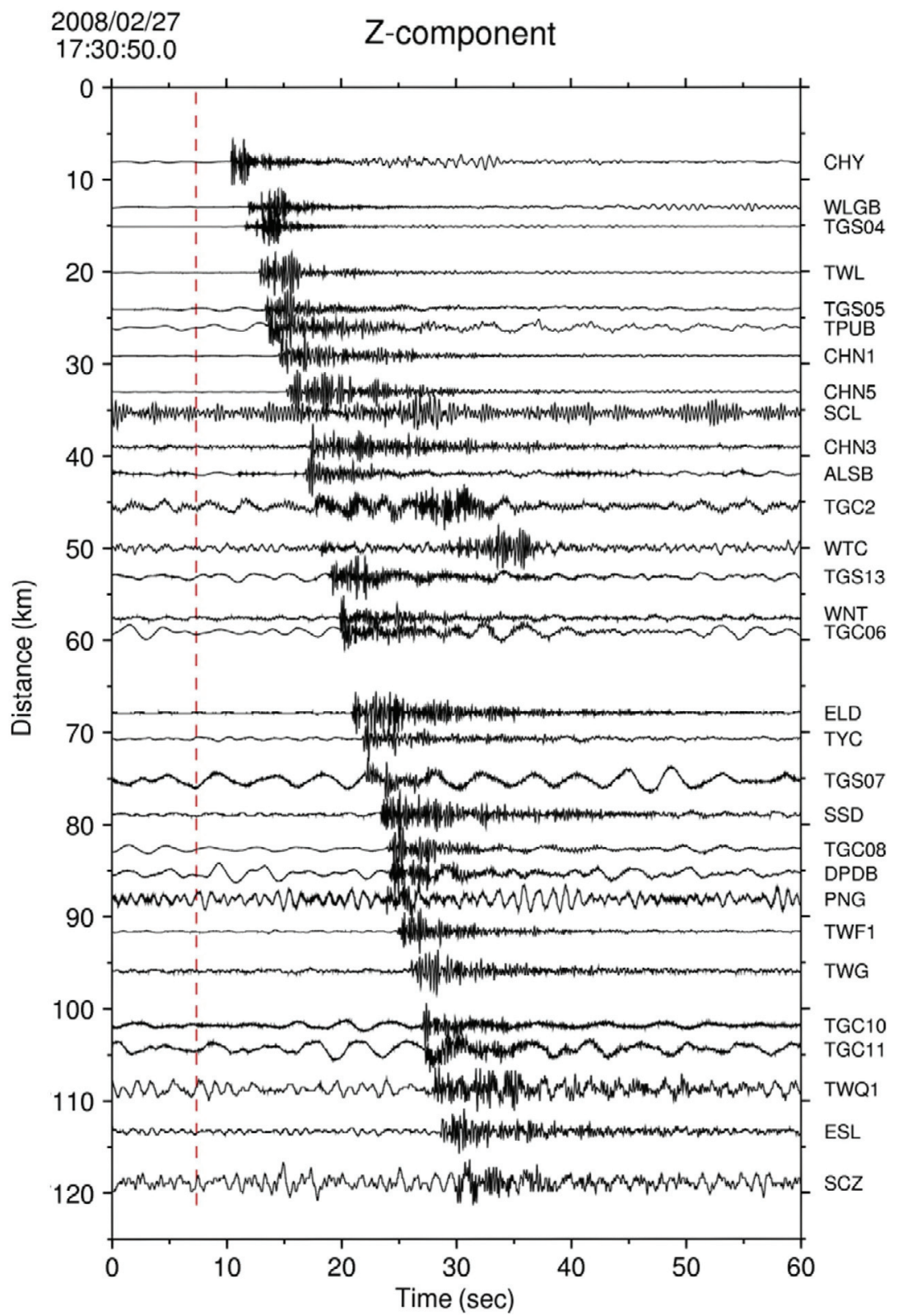

Fig. 2. Vertical component signals caused by site S2 explosion (Table 1) recorded by the CWBSN, BATS and TAIGER stations. 


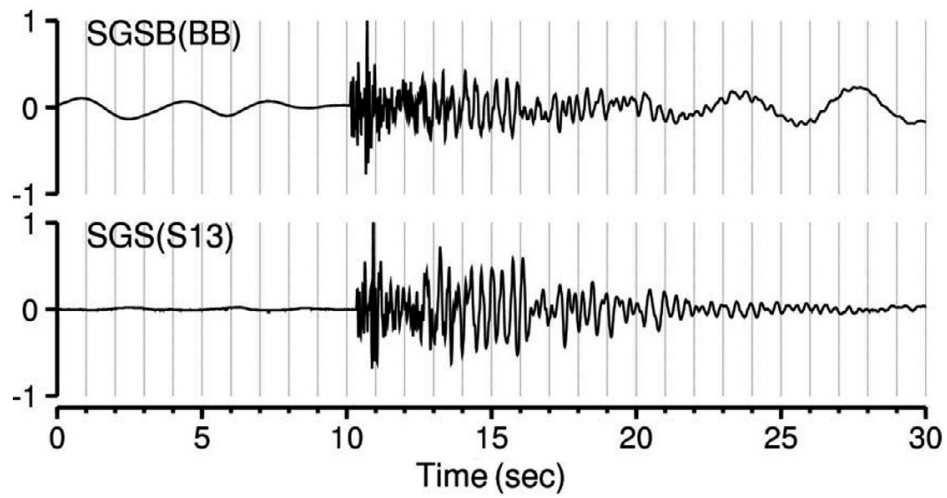

Fig. 3. An example of explosion signals recorded by the co-site stations of the BATS (upper) and CWBSN (bottom) systems.

Table 2. Telemetry delay checked by explosion signals and Chang et al. (2012).

\begin{tabular}{|c|c|c|c|c|c|c|c|c|c|c|}
\hline \multirow{2}{*}{$\begin{array}{c}\text { Station } \\
\text { Code }\end{array}$} & \multicolumn{9}{|c|}{ Explosion site (Latency in sec) } & \multirow{2}{*}{ Test * } \\
\hline & S1 & S2 & S3 & S3P & S4 & N1 & N3 & N3P & N4 & \\
\hline ALS & & & 0.24 & 0.21 & & 0.21 & & & 0.25 & 0.24 \\
\hline CHK & & & & & 0.19 & & & & & 0.21 \\
\hline ECL & & & & & 0.15 & & & & & 0.20 \\
\hline ELD & & & 0.19 & 0.20 & 0.17 & & & & 0.21 & 0.20 \\
\hline ESL & & & & & 0.19 & & 0.22 & 0.19 & 0.18 & 0.21 \\
\hline SGS & & 0.23 & 0.19 & 0.21 & 0.20 & & & & & 0.22 \\
\hline TWB1 & & & & & & 0.17 & & 0.21 & & 0.20 \\
\hline TWG & & & & 0.21 & 0.24 & & & & & 0.20 \\
\hline WGK & 0.20 & 0.20 & 0.22 & & & & & & & 0.21 \\
\hline
\end{tabular}

* Tested by Chang et al. (2012).

results were similar to the results in Chang et al. (2012). Telemetry delays obtained from Chang et al. (2012) were used to correct the selected P arrivals at the CWBSN stations. Corrected $\mathrm{P}$ arrivals at the CWBSN stations were then combined with arrivals from the BATS and TAIGER stations into one database for earthquake location. To test the uncertainty of the earthquake location, the earthquake location approach (Wu et al. 2003), using the three-dimensional velocity model (Wu et al. 2007, 2009) with station correction, was used to locate the explosions. The approach used the 3D ray tracing process proposed by Thurber (1993) for calculating the theoretical travel times of $\mathrm{P}$ and $\mathrm{S}$ waves from one earthquake source to one seismic station in a $3 \mathrm{D}$ velocity medium. Station corrections of P- and S-waves were iteratively obtained and updated by averaging a group of travel residuals at the stations following each iteration in an earthquake relocation (Wu et al. 2008).

\section{RESULTS}

Ten explosion sites were relocated from $\mathrm{P}$ arrivals using the three dimensional velocity models of $\mathrm{Wu}$ et al.
(2007, 2009). Table 3 provides the relocated positions and related parameters. Most of the relocated positions were moved south-eastward and deeper in depth. Since we did not permit the location program to produce an air-quake, whose location in depth was above elevation, it was reasonable for the relocated shots to move deeper. Therefore, the error was attributed to the vertical direction.

Parameters of the ERH, ERZ, RMS, and GAP (the largest separation between any two azimuthally adjacent stations) were used, in general, to estimate the quality of the earthquake location. Therefore, we examined the location errors of the explosion sites using those parameters. Figure 4 displays location errors for explosion sites using the depth, the horizontal, and the hypocenter versus the ERZ, ERH, RMS, and GAP. In general, location errors increase with parameters of the ERZ, ERH, RMS, and GAP. However, Fig. 4 indicates that only the GAP had a positive linear correlation coefficient $(\mathrm{R})$ in regards to location errors. Our results were similar to those reported by Chiu et al. (1997), indicating that the GAP is a number that represents the goodness of spatial coverage for seismic stations relative to source locations. Other parameters, RMS, ERZ, and ERH 
are statistical errors that may not represent real errors in the location accuracy.

Interesting to note is that the location errors associated with explosion sites were largely the result of the poor coverage of seismic stations. In general, the earthquake location case displayed both $\mathrm{P}$ and $\mathrm{S}$ arrivals, which was not the case for explosions. Location shifts of explosions due to the earthquake location process were not close to the true condition. Therefore, for a more realistic testing, we added theoretical S-P times and P arrivals for earthquake location. Considering the weighting of the $\mathrm{S}$ wave for earthquake location, the weighting of theoretical S arrivals was specified

Table 3. Parameters of 10 dynamite shots of the TAIGER project relocated using observed $\mathrm{P}$ arrivals only.

\begin{tabular}{|cccccccccccc|}
\hline $\begin{array}{c}\text { Site } \\
\text { Code }\end{array}$ & $\begin{array}{c}\text { Longitude } \\
\left({ }^{\circ} \mathbf{E}\right)\end{array}$ & $\begin{array}{c}\text { Longitude } \\
\left({ }^{\circ} \mathbf{N}\right)\end{array}$ & $\begin{array}{c}\text { Depth } \\
(\mathbf{k m})\end{array}$ & $\begin{array}{c}\text { ERH } \\
(\mathbf{k m})\end{array}$ & $\begin{array}{c}\text { ERZ } \\
(\mathbf{k m})\end{array}$ & $\begin{array}{c}\text { RMS } \\
(\mathbf{s e c})\end{array}$ & $\begin{array}{c}\text { GAP } \\
\left({ }^{\circ}\right)\end{array}$ & $\begin{array}{c}\text { ErrX* } \\
(\mathbf{k m})\end{array}$ & $\begin{array}{c}\text { ErrY* } \\
(\mathbf{k m})\end{array}$ & $\begin{array}{c}\text { ErrZ* } \\
(\mathbf{k m})\end{array}$ & $\begin{array}{c}\text { No. of } \\
\mathbf{s t a t i o n s}\end{array}$ \\
\hline S1 & 120.243 & 23.506 & 7.30 & 0.16 & 0.11 & 0.18 & 84 & 1.29 & -0.49 & 7.31 \\
S2 & 120.429 & 23.419 & 4.54 & 0.10 & 0.10 & 0.16 & 45 & 1.62 & -0.68 & 4.56 & 85 \\
S3 & 120.727 & 23.280 & 0.34 & 0.18 & 0.40 & 0.22 & 37 & 2.10 & -0.17 & 0.99 & 50 \\
S3P & 120.624 & 23.141 & 3.85 & 0.23 & 0.21 & 0.20 & 88 & 0.56 & 0.27 & 4.18 & 33 \\
S4 & 121.133 & 23.138 & 4.42 & 0.25 & 0.22 & 0.27 & 51 & -0.01 & 0.31 & 4.81 & 70 \\
N1 & 121.041 & 24.790 & 3.78 & 0.19 & 0.14 & 0.21 & 47 & 0.34 & -0.59 & 3.84 \\
N2 & 121.232 & 24.662 & 0.53 & 0.26 & 0.49 & 0.21 & 43 & 0.48 & -1.71 & 1.12 \\
N3 & 121.480 & 24.574 & 2.49 & 0.22 & 0.49 & 0.23 & 60 & 0.06 & -0.49 & 2.89 & 54 \\
N3P & 121.482 & 24.572 & 2.04 & 0.21 & 0.39 & 0.25 & 46 & 0.22 & -0.78 & 2.44 & 78 \\
N4 & 121.793 & 24.439 & 6.01 & 0.42 & 0.20 & 0.23 & 178 & -1.10 & -1.06 & 6.02 & 63 \\
\hline
\end{tabular}

* ErrX, ErrY, and ErrZ are the differences of relocated positions between the actual explosion sites in longitude, latitude and depth, respectively. Positive values are in the directions of east, north, and relative depth for $\operatorname{Err} X, \operatorname{Err} Y$, and ErrZ, respectively.

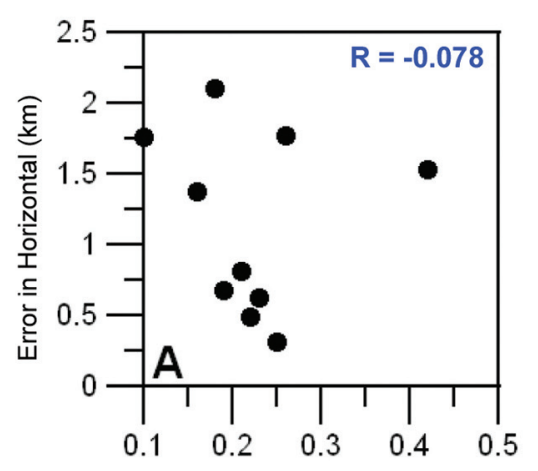

Statistical Error in Horizontal, ERH (km)

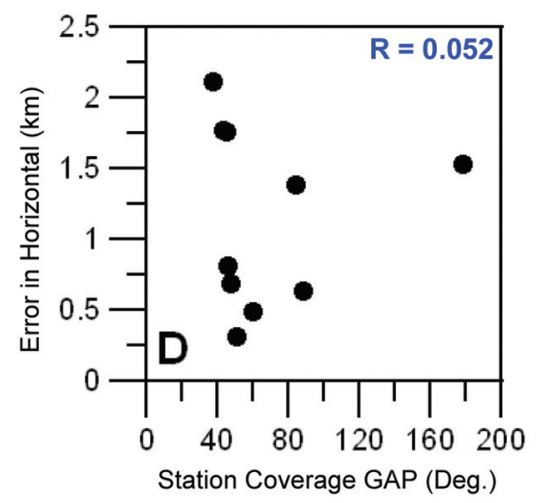

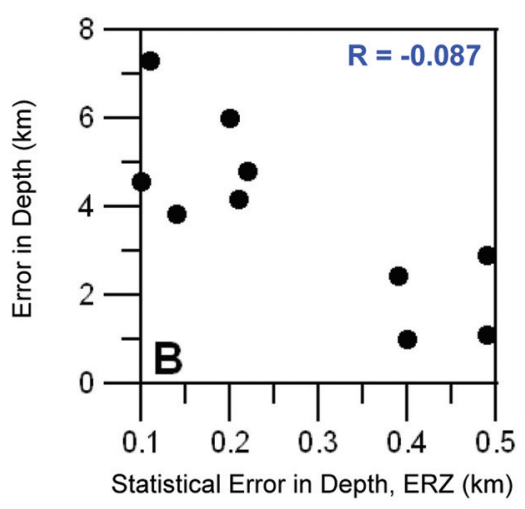
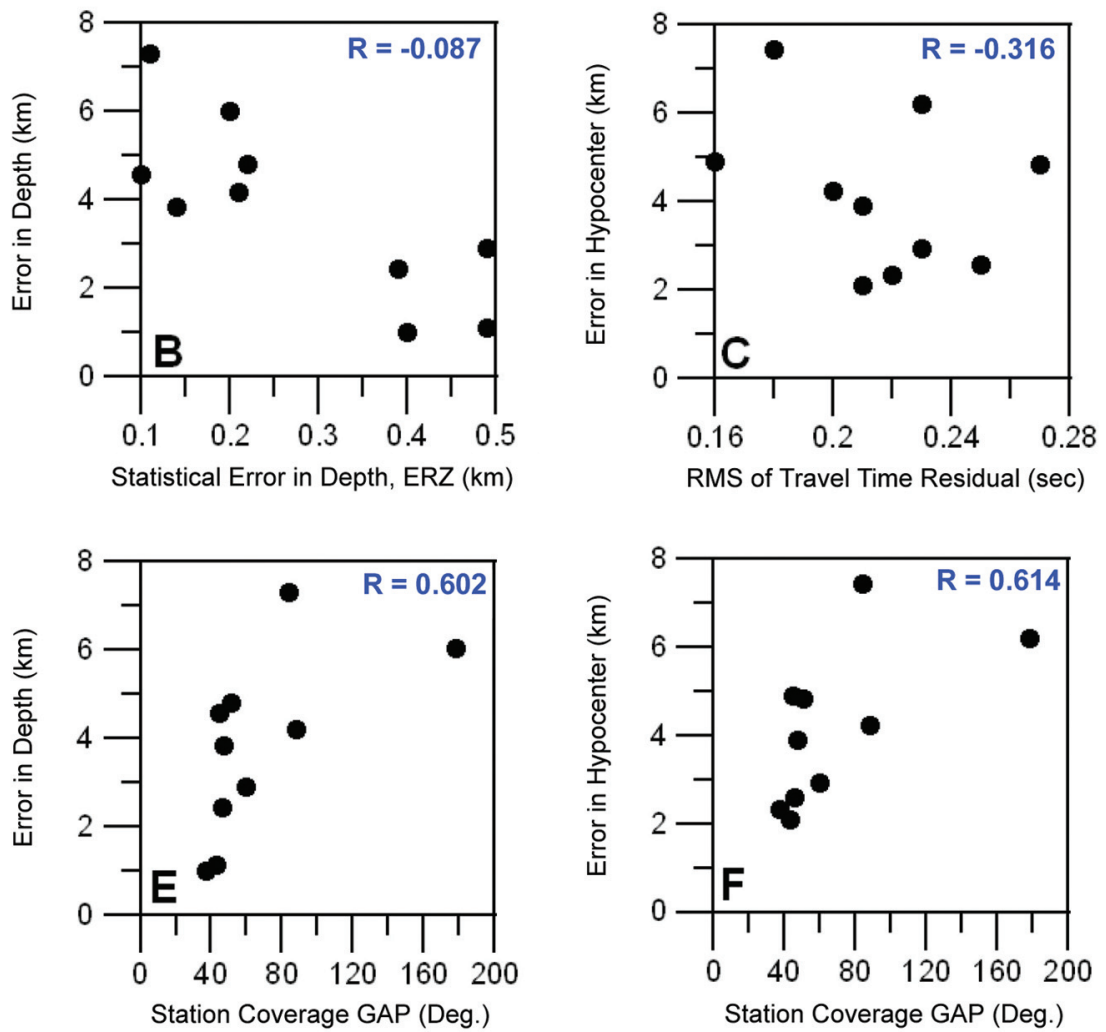

Fig. 4. Location errors of explosion sites in depth, horizontal, and hypocenter versus statistical error in depth (ERZ), in horizontal (ERH), root-mean square of travel time residuals (RMS), and station coverage gap (GAP) for using observed P arrivals only. R shows the value of linear correlation coefficient. 
as one degree higher than $\mathrm{P}$ arrivals because there were five degrees of quality (degree 0 to 4 ) from good to poor, respectively, in the selection strategy of the CWBSN. As a result, one degree higher indicates poorer quality, as is normal for S-waves. The selection quality was then used as a weighting parameter for earthquake location. Table 4 contains relocated positions with the addition of theoretical S arrivals and related parameters. Comparing the results of Table 3, the values of the RMS were larger than those that only used $\mathrm{P}$ arrivals for locating explosions. Most of the relocated sites moved southeastward as the $\mathrm{P}$ arrival results, while errors in the horizontal (ERH) position did not change significantly; however, errors in depth became much smaller than those that using only observed $\mathrm{P}$ arrivals for the locating process. Figure 5 provides location errors for the explosion sites based on the depth, the horizontal, and the hypocenter versus the ERZ, ERH, RMS, and GAP when using observed $\mathrm{P}$ and theoretical $\mathrm{S}$ arrivals. Location errors had better relationships with those parameters, especially for the GAP. The hypocenter location error (Herr) and the GAP had a linear correlation coefficient of $\mathrm{R}=0.821$. We determined a linear relationship between the Herr and GAP, as follows:

Herr $=0.031 \mathrm{GAP}+0.294$

with a standard deviation of 1.02 . The units of Herr and GAP are provided in $\mathrm{km}$ and degrees, respectively.

\section{DISCUSSION}

Most of the relocated positions were moved southeastward. We suggest that the result may be due to a velocity model problem. Coastal plains and mountain ranges are distributed in the western portion, and on the central and eastern sides of Taiwan, respectively (Fig. 1). Differences in rock properties between these two regions can be determined in terms of the seismic velocities as follows. The coastal plains and the mountain regions (Fig. 1) are relatively low and high, respectively (Kim et al. 2005; Wu et al. 2007, 2009; Kuo-Chen et al. 2012). In such regions, the velocity model we used may not have enough low and high seismic-wave speeds in such regions. Therefore, most of the relocated positions were moved eastward. For the positions which were moved southward, the same situation may have resulted due to the differences in the Moho depths. In southern Taiwan, the Moho depth is relatively shallower than that in central-northern Taiwan (Kim et al. 2005; Wu et al. 2007; Kuo-Chen et al. 2012; Ustaszewski et al. 2012) indicating that the average velocity in southern Taiwan is higher than that in central-northern Taiwan. Therefore, most of the relocated positions may move southward as well.

In general, location errors should increase with the GAP, ERH, ERZ, and RMS. However, our results indicated that only the GAP had a good relationship but that other parameters were not so clear. Therefore, we removed estimated location errors using GAP in Eq. (1) and then checked the residuals versus the ERH, ERZ, and RMS again (Fig. 6). The results indicated that positive linear correlation coefficients were found. Therefore, based on this result we can express the location error, as follows:

Herr $=\mathrm{A} \cdot \mathrm{GAP}+\mathrm{B} \cdot \mathrm{ERHZ}+\mathrm{C} \cdot \mathrm{RMS}+\mathrm{D}$

where A, B, C, and D are constants. ERHZ is $\sqrt{\mathrm{ERH}^{2}+\mathrm{ERZ}^{2}}$. Values of the location error in Table 4 were used for the regression. The location error relationship was determined as follows:

Herr $=0.0323 \mathrm{GAP}+6.567 \mathrm{ERHZ}+2.895 \mathrm{RMS}-2.667$

with a standard deviation of $0.814 \mathrm{~km}$. Figure 7 provides the relationship of the hypocentral errors between actual and calculated explosion sites. Using this relationship, we could estimate the location errors. We further analyzed the

Table 4. Parameters of 10 dynamite shots of the TAIGER project relocated using observed $\mathrm{P}$ and theoretical S arrivals.

\begin{tabular}{|ccccccccccc|}
\hline $\begin{array}{c}\text { Site } \\
\text { Code }\end{array}$ & $\begin{array}{c}\text { Longitude } \\
\left({ }^{\circ} \mathbf{E}\right)\end{array}$ & $\begin{array}{c}\text { Longitude } \\
\left({ }^{\circ} \mathbf{N}\right)\end{array}$ & $\begin{array}{c}\text { Depth } \\
(\mathbf{k m})\end{array}$ & $\begin{array}{c}\text { ERH } \\
(\mathbf{k m})\end{array}$ & $\begin{array}{c}\text { ERZ } \\
(\mathbf{k m})\end{array}$ & $\begin{array}{c}\text { RMS } \\
(\mathbf{s e c})\end{array}$ & $\begin{array}{c}\text { GAP } \\
\left({ }^{\circ}\right)\end{array}$ & $\begin{array}{c}\text { ErrX } \\
(\mathbf{k m})\end{array}$ & $\begin{array}{c}\text { ErrY } \\
(\mathbf{k m})\end{array}$ & $\begin{array}{c}\text { ErrZ } \\
(\mathbf{k m})\end{array}$ \\
\hline S1 & 120.225 & 23.488 & 0.92 & 0.18 & 0.12 & 0.43 & 86 & -0.50 & -2.50 & 0.93 \\
S2 & 120.424 & 23.419 & 0.17 & 0.15 & 0.18 & 0.41 & 40 & 1.11 & -0.66 & 0.19 \\
S3 & 120.729 & 23.283 & -1.24 & 0.21 & 0.44 & 0.37 & 43 & 2.34 & 0.12 & -0.59 \\
S3P & 120.618 & 23.135 & 5.22 & 0.26 & 0.22 & 0.33 & 90 & -0.03 & -0.38 & 5.55 \\
S4 & 121.135 & 23.125 & -0.54 & 0.21 & 0.25 & 0.38 & 35 & 0.14 & -1.13 & -0.15 \\
N1 & 121.041 & 24.793 & 1.43 & 0.14 & 0.19 & 0.34 & 48 & 0.39 & -0.28 & 1.48 \\
N2 & 121.233 & 24.663 & -0.65 & 0.21 & 0.25 & 0.25 & 42 & 0.51 & -1.56 & -0.06 \\
N3 & 121.481 & 24.574 & -0.77 & 0.16 & 0.18 & 0.27 & 44 & 0.10 & -0.54 & -0.36 \\
N3P & 121.482 & 24.572 & -0.77 & 0.13 & 0.15 & 0.27 & 44 & 0.27 & -0.76 & -0.36 \\
N4 & 121.809 & 24.438 & 5.19 & 0.25 & 0.13 & 0.27 & 189 & 0.57 & -1.22 & 5.20 \\
\hline
\end{tabular}




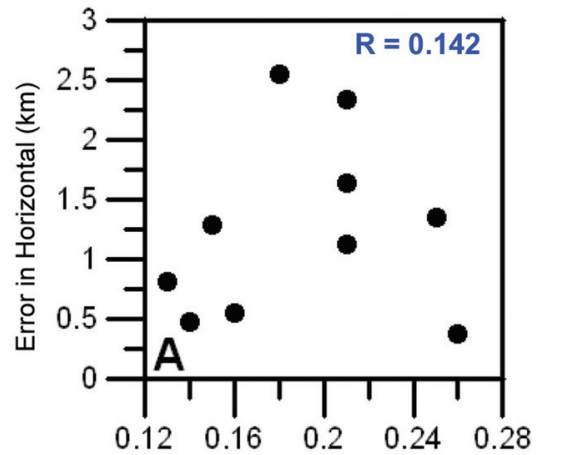

Statistical Error in Horizontal, ERH (km)

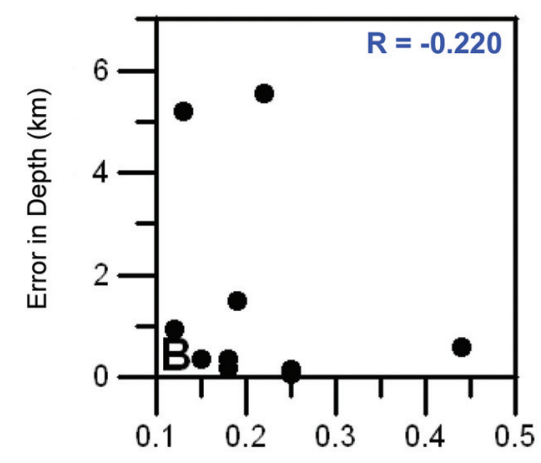

Statistical Error in Depth, ERZ $(\mathrm{km})$
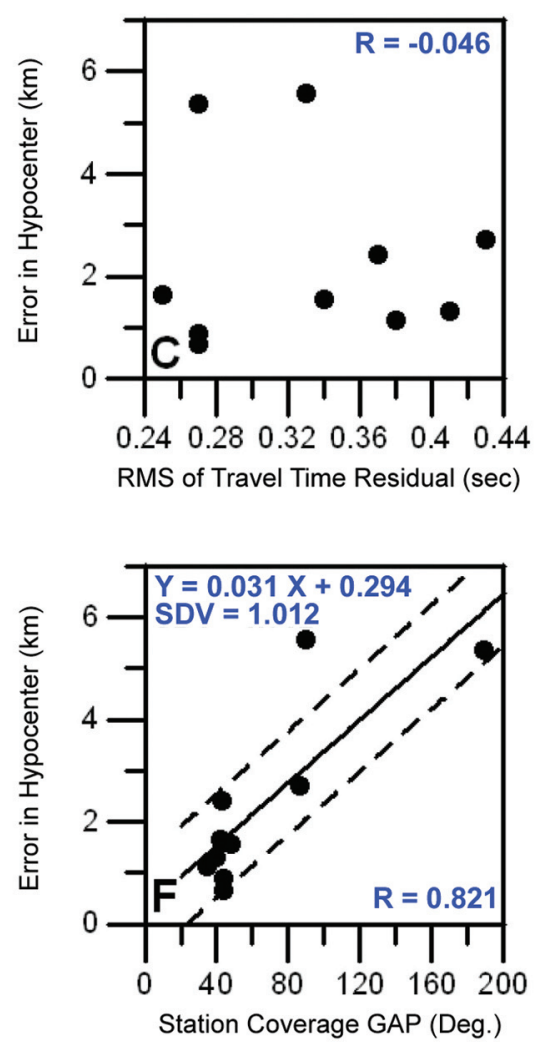

Fig. 5. Location errors of explosion sites in depth, horizontal, and hypocenter versus ERZ, ERH, RMS, and GAP for using observed P and theoretical $\mathrm{S}$ arrivals. R shows the value of linear correlation coefficient.
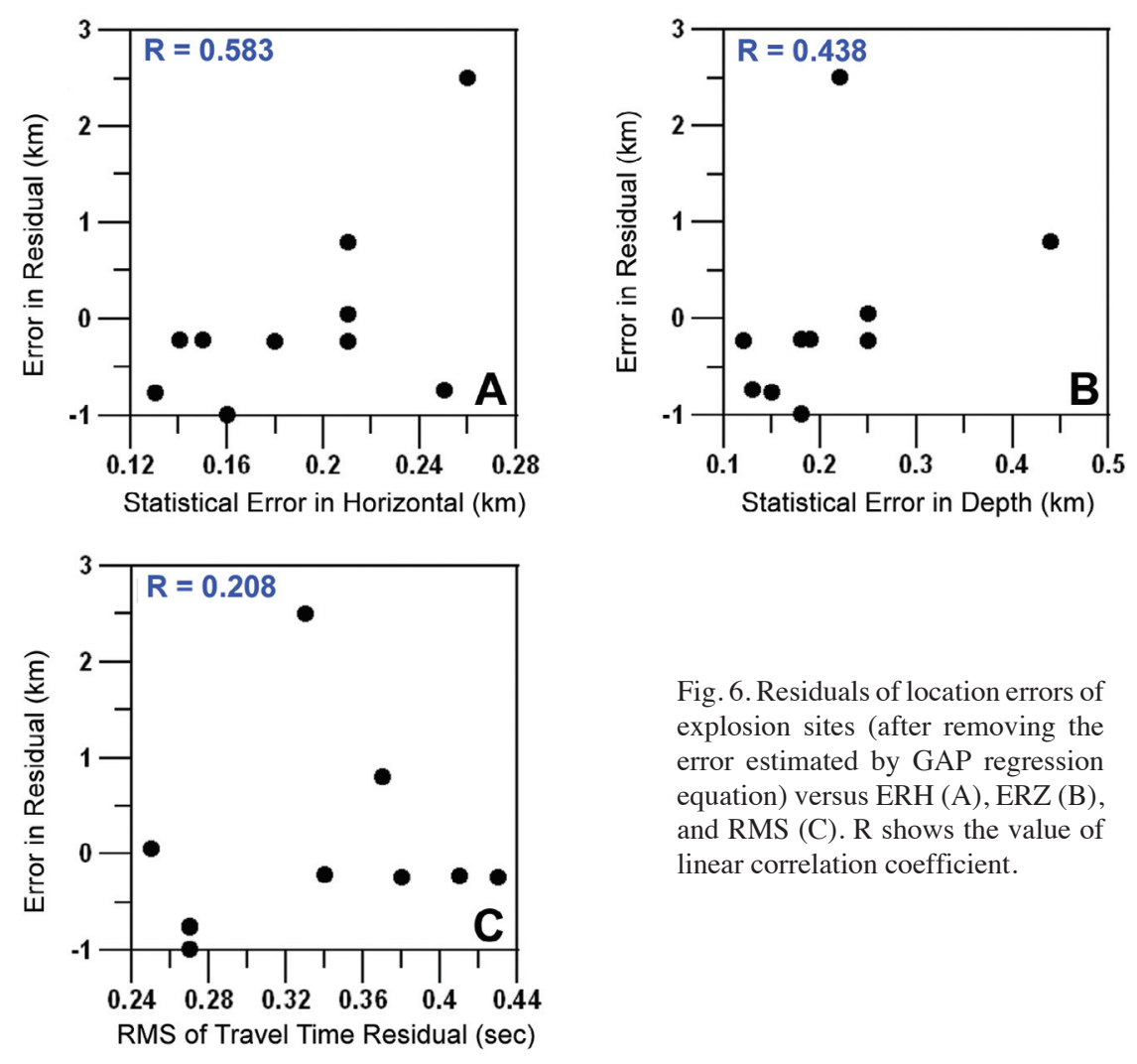

Fig. 6. Residuals of location errors of explosion sites (after removing the error estimated by GAP regression equation) versus ERH (A), ERZ (B), and RMS (C). R shows the value of linear correlation coefficient. 


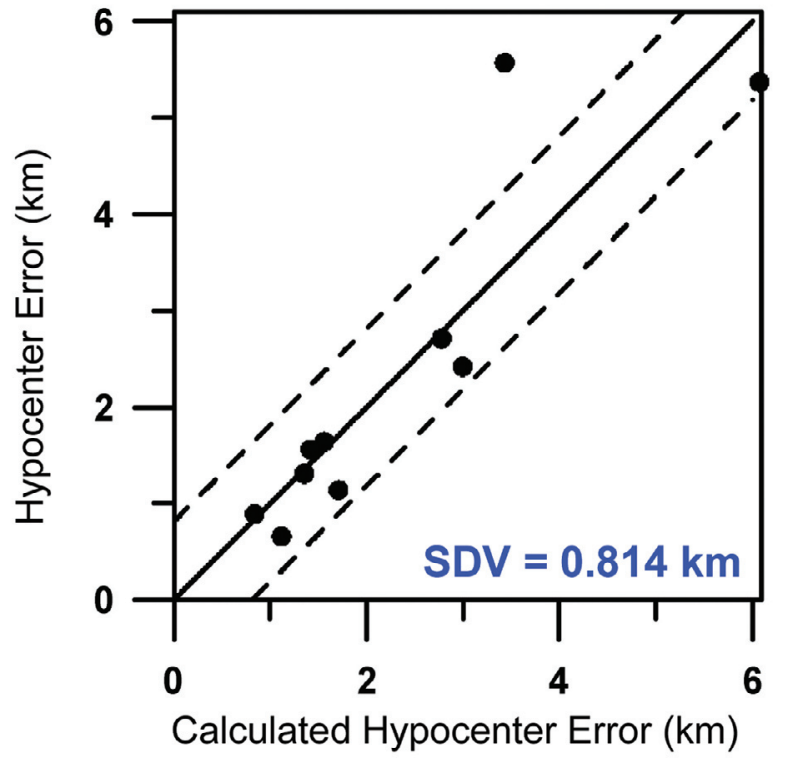

Fig. 7. The relationship between location errors and calculated errors of explosion sites. Solid line shows 1:1 line and two dashed lines show the range of one standard deviation.

hypocenter versus depth errors for the ten explosion sites (Fig. 8) and found that the depth error was approximately 0.8 times that of the hypocentral error. We could then determine that the horizontal error was approximately 0.6 times that of the hypocentral error. Statistical measurements of standard errors in longitude (ERX) and latitude (ERY), calculated based on the earthquake location program (Flinn 1965; Lee and Lahr 1975), were used for estimating the errors in longitude and latitude. Using Eq. (3) we estimated the hypocentral location error, Herr, then obtained new location errors in depth (ERZn), longitude (ERXn), and latitude (ERYn), as follows:

$\mathrm{ERZn}=0.8$ Herr

$\mathrm{ERXn}=0.6 \mathrm{Herr} \times \mathrm{ERX} / \sqrt{\mathrm{ERX}^{2}+\mathrm{ERY}^{2}}$

$\mathrm{ERYn}=0.6 \mathrm{Herr} \times \mathrm{ERY} / \sqrt{\mathrm{ERX}^{2}+\mathrm{ERY}^{2}}$

Using these relationships, we could estimate location errors in the CWBSN catalog. Using estimations of hypocenter error, one standard deviation of the fitting was approximately $0.8 \mathrm{~km}$. Therefore, when the Herr value was less than $0.8 \mathrm{~km}$, we still assume that the Herr was $0.8 \mathrm{~km}$.

A total of 384064 events from 1991 to 2011 in Taiwan were relocated using a 3-D seismic velocity model by combining P and S arrivals from CWBSN, BATS, and Japan Meteorological Agency (JMA) stations in the southern Ryukyu Island chain, as well as S-P times from the stations of the Taiwan Strong-Motion Instrumentation Program (Wu et al. 2008). Location errors in depth, longitude, and latitude

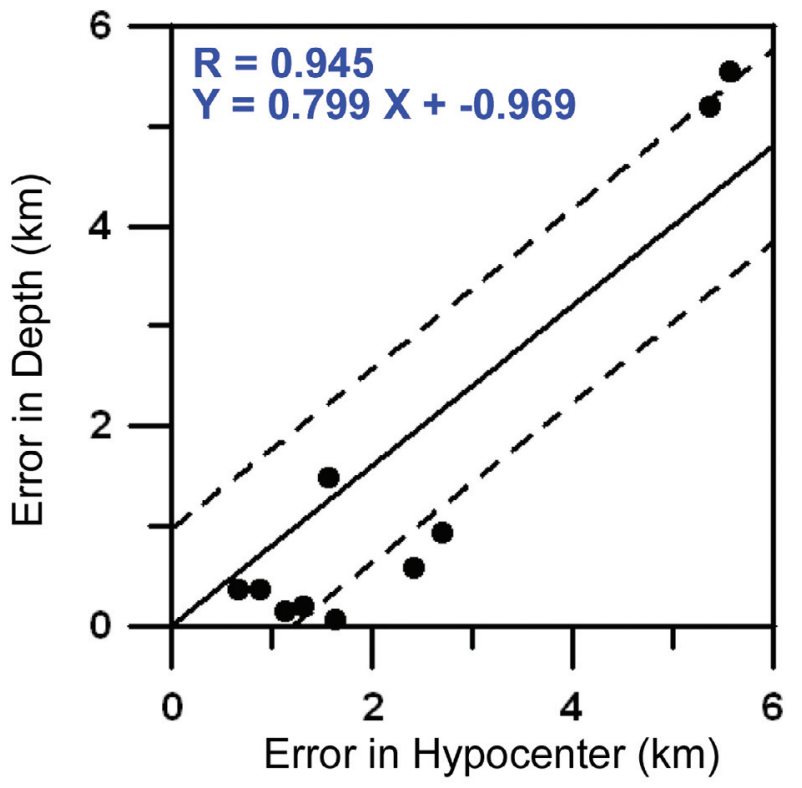

Fig. 8. The relationship between relocated hypocenter errors and depth errors of explosion sites. Solid line shows fitted line and two dashed lines show the range of one standard deviation.

were calculated from the relationships mentioned above. Figures $9 \mathrm{a}-\mathrm{c}$ provide the distribution of average location errors for longitude, latitude, and depth, respectively. Based on our results, the GAP is a major contributor for estimating location errors. Therefore, location errors for the earthquake locations on land were smaller than those offshore. However, the region near the southern Ryukyu Island chain displayed much smaller values due to the addition of JMA stations. Based on this relationship, the major error is distributed to depth. Therefore, errors in depth were larger than those for longitude and latitude. Due to the elongation of the island of Taiwan in latitude, with a larger span in seismic station distribution, errors in latitude were smaller than those for longitude. For the inland region, location errors in longitude, latitude, and depth were approximately $3.1 \pm 2.7$, $1.3 \pm 1.6$, and $4.6 \pm 3.9 \mathrm{~km}$, respectively. Errors were larger in the area outside of the island by approximately $4.3 \pm 2.9$, $1.4 \pm 1.6$, and $6.3 \pm 4.1 \mathrm{~km}$, respectively. The southwestern and northeastern offshore areas were two regions with larger location errors.

\section{CONCLUSIONS}

In this study we investigated the errors associated with earthquakes located in the region of Taiwan. By locating the explosions, we determined that the main uncertainty in location was associated with the depth direction, and that even the 3D velocity model was used. However, the relocated explosion sites that shifted southeastward may have been caused by the difference in velocity structures. Using 
(a)

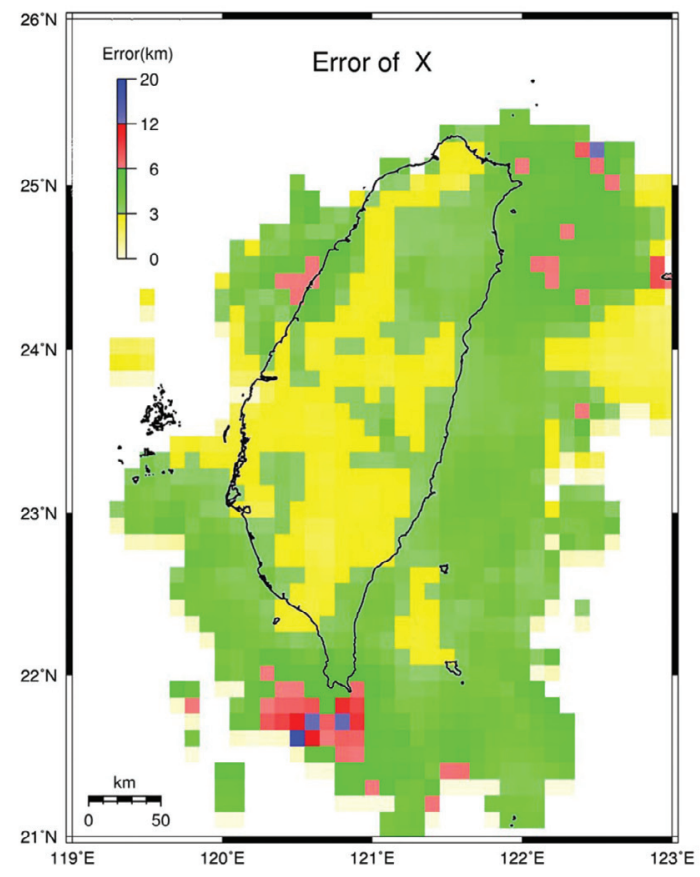

(c)

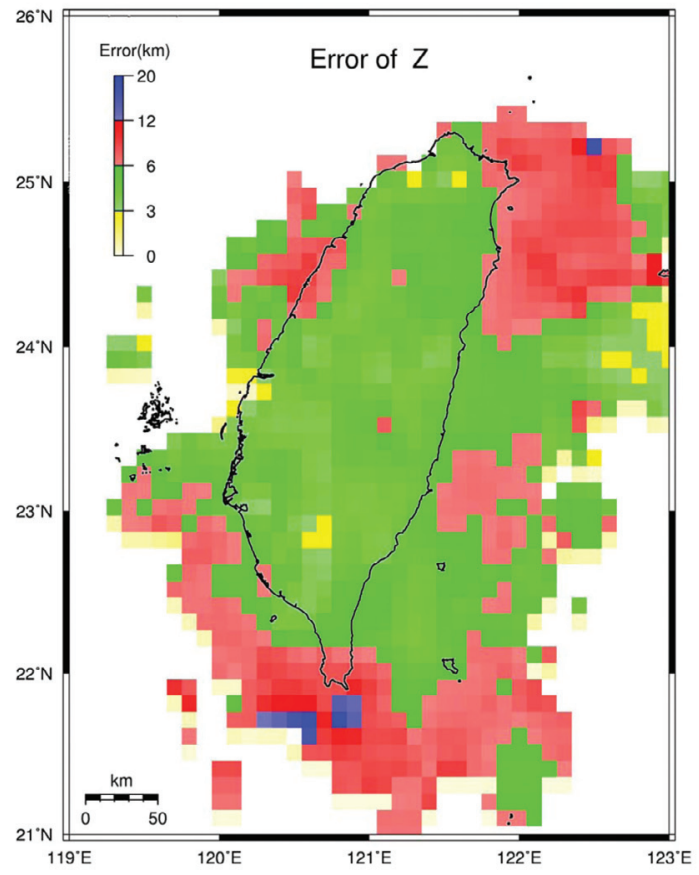

(b)

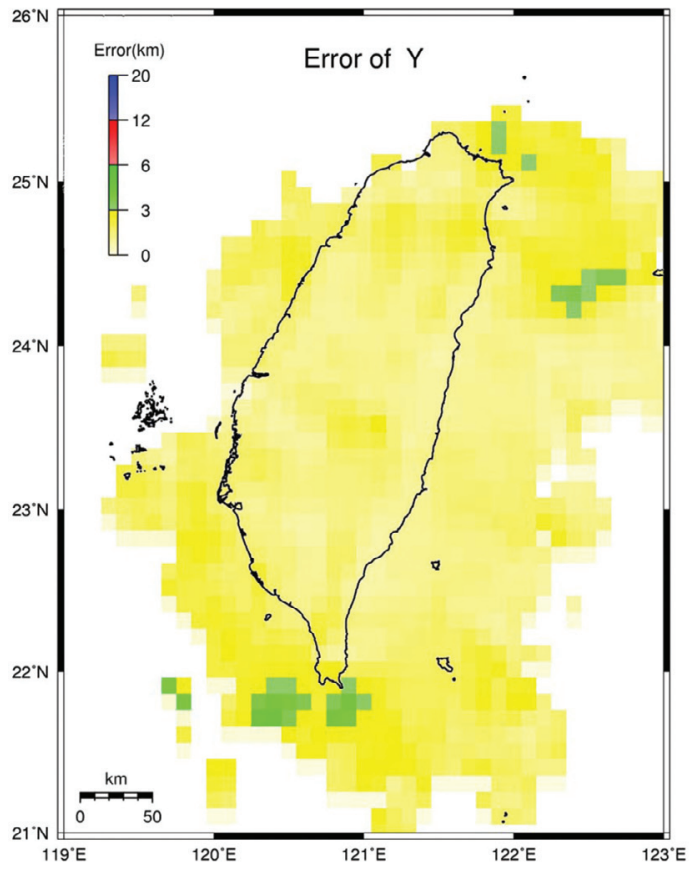

Fig. 9. (a) Distribution of the location errors of the averaged earthquake in longitude estimated in this study. (b) Distribution of the location errors of the averaged earthquake in latitude estimated in this study. (c) Distribution of the location errors of the averaged earthquake in depth estimated in this study.

explosion records, errors in the locations could be estimated in terms of the GAP, ERH, ERZ, and RMS. Moreover, in this study, the errors associated with earthquake locations were also estimated. Understanding the uncertainty associated with the earthquake location will benefit seismotectonics and seismic hazard mitigation studies. The relocated earthquake catalog that contains location errors for depth, longitude, and latitude is available by request (contact YihMin Wu, E-mail: drymwu@ntu.edu.tw).
Acknowledgements This research was supported by the Central Weather Bureau and National Science Council. The GMT software from Wessel and Smith (1998) was used in plotting part of the figures and is gratefully acknowledged. The authors wish to thank Dr. M. Nakamura and the Japan Meteorological Agency for providing the arrival time readings. We also wish to thank Prof. Jer-Ming Chiu and one anonymous reviewer for providing very constructive comments. 


\section{REFERENCES}

Chang, C. H., Y. M. Wu, T. C. Shin, and C. Y. Wang, 2000: Relocation of the 1999 Chi-Chi earthquake in Taiwan. Terr. Atmos. Ocean. Sci., 11, 581-590.

Chang, C. H., Y. M. Wu, D. Y. Chen, T. C. Shin, T. L. Chin, and W. Y. Chang, 2012: An examination of telemetry delay in the Central Weather Bureau Seismic Network. Terr. Atmos. Ocean. Sci., 23, 261-268, doi: 10.3319/ TAO.2011.11.29.01(T). [Link]

Chiu, J. M., S. C. C. Chiu, and S. G. Kim, 1997: The significance of the crustal velocity model in local earthquake locations from a case example of a PANDA experiment in the Central United States. Bull. Seismol. Soc. Am., 87, 1537-1552.

Flinn, E. A., 1965: Confidence regions and error determinations for seismic event location. Rev. Geophys., 3, 157185, doi: 10.1029/RG003i001p00157. [Link]

Kim, K. H., J. M. Chiu, J. Pujol, K. C. Chen, B. S. Huang, Y. H. Yeh, and P. Shen, 2005: Three-dimensional $V_{p}$ and $V_{s}$ structural models associated with the active subduction and collision tectonics in the Taiwan region. Geophys. J. Int., 162, 204-220, doi: 10.1111/j.1365246X.2005.02657.x. [Link]

Kuo-Chen, H., F. T. Wu, and S. W. Roecker, 2012: Threedimensional P velocity structures of the lithosphere beneath Taiwan from the analysis of TAIGER and related seismic data sets. J. Geophys. Res., 117, B06306, doi: 10.1029/2011JB009108. [Link]

Lee, W. H. K. and J. C. Lahr, 1975: HYPO71 (Revised): A computer program for determining hypocenter, magnitude, and first motion pattern of local earthquakes. US Geological Survey Open-File Report 75-311, 113 pp.

Thurber, C. H., 1993: Local earthquake tomography: Velocities and $\mathrm{Vp} / \mathrm{Vs}$ - Theory. In: Iyer, H. M. and K. Hirahara (Eds.), Seismic Tomography: Theory and
Practice, 563-583, Chapman and Hall, London.

Wessel, P. and W. H. F. Smith, 1998: New, improved version of generic mapping tools released. Eos, Trans., $A G U, 79$, p 579, doi: 10.1029/98EO00426. [Link]

Wu, Y. M., N. C. Hsiao, T. L. Teng, and T. C. Shin, 2002: Near real-time seismic damage assessment of the rapid reporting system. Terr. Atmos. Ocean. Sci., 13, 313324.

Wu, Y. M., C. H. Chang, N. C. Hsiao, and F. T. Wu, 2003: Relocation of the 1998 Rueyli, Taiwan, earthquake sequence using three-dimensions velocity structure with stations corrections. Terr. Atmos. Ocean. Sci., 14, 421430.

Wu, Y. M., C. H. Chang, L. Zhao, J. B. H. Shyu, Y. G. Chen, K. Sieh, and J. P. Avouac, 2007: Seismic tomography of Taiwan: Improved constraints from a dense network of strong motion stations. J. Geophys. Res., 112, B08312, doi: 10.1029/2007JB004983. [Link]

Wu, Y. M., C. H. Chang, L. Zhao, T. L. Teng, and M. Nakamura, 2008: A Comprehensive Relocation of Earthquakes in Taiwan from 1991 to 2005. Bull. Seismol. Soc. Am., 98, 1471-1481, doi: 10.1785/0120070166. [Link]

Wu, Y. M., J. B. H. Shyu, C. H. Chang, L. Zhao, M. Nakamura, and S. K. Hsu, 2009: Improved seismic tomography offshore northeastern Taiwan: Implications for subduction and collision processes between Taiwan and the southernmost Ryukyu. Geophys. J. Int., 178, 1042-1054, doi: 10.1111/j.1365-246X.2009.04180.x. [Link]

Ustaszewski, K., Y. M. Wu, J. Suppe, H. H. Huang, C. H. Chang, and S. Carena, 2012: Crust - Mantle boundaries in the Taiwan - Luzon arc-continent collision system determined from local earthquake tomography and 1D models: Implications for the mode of subduction polarity reversal. Tectonophysics, 578, 31-49, doi: 10.1016/j.tecto.2011.12.029. [Link] 